\title{
Addressing Antimicrobial Resistance in Nepal: A Call for Collaborative Efforts
}

\author{
Sitaram Khadka1*, Santoshi Giri² \\ Author Info: \\ ${ }^{1}$ Shree Birendra Hospital; Nepalese Army Institute of Health Sciences, Kathmandu, Nepal \\ ${ }^{2}$ Nepal Public Health Research and Development Center, Kathmandu, Nepal \\ *Corresponding Author: Sitaram Khadka; \\ Email: sitaram.khadka@naihs.edu.np; sitaramkhadka5693@gmail.com; Contact: +977-9851077589
}

Being one of the most important discoveries of medical sciences, antibiotics are, no doubt, considered life-saving drugs. However, antimicrobial resistance (AMR) intimidates the advancement in medical science posing a substantial risk to lives. ${ }^{1}$ Currently, around 700,000 people die each year due to drug-resistant diseases that might reach up to 10 million deaths annually by 2050 if remain unchecked. ${ }^{2}$ It is also estimated that by 2030, AMR would force about 24 million people into extreme poverty. AMR is no longer a concern for the distant future but is a global pressing issue that requires immediate attention. ${ }^{3}$ WHO has declared AMR as one of the top 10 global public health threats facing humanity. ${ }^{4}$

AMR has been increasing alarmingly globally. Most bacterial pathogens have shown high resistance to the majority of first- and some second-line antibiotics. ${ }^{5}$ The Global Antimicrobial Resistance and Use Surveillance System (GLASS) report 2019 reported that Escherichia coli and Klebsiella pneumoniae causing UTIs showed $54.4 \%$ and $43.1 \%$ resistance to the first-line antibiotic cotrimoxazole and $43.1 \%$ and $36.4 \%$ for ciprofloxacin, the $2^{\text {nd }}$ option drug respectively. ${ }^{6}$

The upsurge in AMR has been reported by several studies in low-and middle-income countries (LMICs),
Nepal is one of them. According to a recent study, the group of bacteria that have developed resistance against antibiotics are predominantly Enterococcus faecium, Staphylococcus aureus, $K$ pneumoniae, Acinetobacter baumanni, Pseudomonas aeruginosa, and Enterobacter spp. (ESKAPE) in humans and E coli, Salmonella spp., Staphylococcus spp., Streptococcus spp., Pasteurella spp., and Pseudomonas spp. in animals. National AMR Surveillance report 2017 reported that some of the microorganisms have developed 100 percent resistance to the antibiotics of interest: Salmonella spp. with ciprofloxacin and levofloxacin; ESBL producing E. coli with ampicillin, ciprofloxacin, norfloxacin, ceftriaxone, and levofloxacin; MRSA with erythromycin and ciprofloxacin; MDR Klebsiella spp with amoxicillin, cotrimoxazole, amoxicillin/ clavulanic acid, levofloxacin, ceftazidime, gentamicin, imipenem, ciprofloxacin, ceftriaxone, and amikacin; and MDR Acinetobacter with cotrimoxazole, ceftazidime, gentamicin, ciprofloxacin, piperacillin/ tazobactam, amikacin, imipenem, tobramycin. ${ }^{7}$ The situation has been further worsened by the lack of discovery of new highly effective antibiotics. ${ }^{5}$

AMR is a natural phenomenon that gets accelerated by irrational use of antimicrobials in the fields of public health, animal, food, agriculture, and aquaculture compounded by poor health care

\begin{tabular}{|c|c|}
\hline QR Code & Article Info \\
\hline \multirow{2}{*}{$\begin{array}{l}\text { Scan Me for } \\
\text { Full Text }\end{array}$} & Published Online: 29 July 2021 \\
\hline & How to cite this article in Vancouver Style? \\
\hline \multirow{2}{*}{ 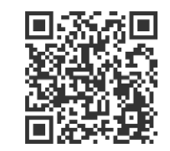 } & $\begin{array}{l}\text { Khadka S, Giri S. Addressing Antimicrobial Resistance in Nepal: A Call for Collaborative Efforts. Europasian J Med Sci. 2021; } \\
\text { 3(2):1-3 https://doi.org/10.46405/ejms.v3i2.354 }\end{array}$ \\
\hline & Disclaimer \\
\hline \multirow[t]{2}{*}{ 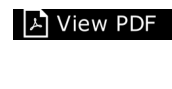 } & Conflict of Interest: None Declared; \\
\hline & Publisher's Note \\
\hline $\begin{array}{l}\text { Copyright (C } 2021 \\
\text { licenses/by/4.0/) } \\
\text { be downloaded fre } \\
\text { published articles, }\end{array}$ & $\begin{array}{l}\text { huthor(s). This work is licensed under the terms and condition of Creative Commons Attribution International License } 4.0 \text { @ (1) (http://creativecommons.org/ } \\
\text { h permits unrestricted use, distribution, and reproduction in any medium, provided the original work is properly cited. This is an open access publication, and can } \\
\text { from the website of the Journal: www.europasianjournals.org. The Journal as well as publisher remain neutral with regards to any jurisdictional claims in any } \\
\text { ontents and the institutional affiliations of the authors. The Europasian Journal of Medical Sciences (EJMS) is an official Journal of Nirvana Psychosocial Care Center \& } \\
\text { vw.nirvanapscc.com). }\end{array}$ \\
\hline
\end{tabular}


systems and weak infection control and preventive measures. The "Silent Tsunami", as referred to globally, is not only the concern of human health as veterinary use of antibiotics is very high. ${ }^{8}$ The agricultural use of antibiotics is highly unregulated and rampant. Studies have shown that even reserved antibiotics of human medicine like colistin are also used rampantly in veterinary. ${ }^{9}$ Humans and animals share the environment they live in and also several pathogens. Therefore, there is a high chance of the transmission of resistant bacteria from animals to humans through a variety of routes making the environment and animals the reservoirs of resistant bacteria. Overuse and underuse of antimicrobials, self-medication practices, lack of well-equipped healthcare facilities are the drivers of AMR development in humans. Similarly, poor animal husbandry with a lack of awareness on good management practices (GMP) along with irrational use of antibiotics is the contributing factor of AMR development in the animal health sector. As the drivers of AMR come from a different sector, the containment strategies also call for a concerted multisectoral approach.

To tackle the issue of AMR, many rules, regulations, and protocols have been developed globally. The discussion undertaken in United Nations Generally Assembly itself speaks about the seriousness of the issue. Development of Global Action Plan (GAP) on Antibiotic Resistance, 2015 and a consensus of all members to adopt National Action Plan (NAP) based on the GAP give momentum to the discourse. ${ }^{10,11}$ The GAP has outlined 5 strategic objectives: effective communication, education, and training; surveillance and research; effective sanitation, hygiene, and infection prevention measures; optimization in antibiotics use; and investment in new medicines, diagnostic tools, vaccines, and other interventions that help contain AMR. ${ }^{11}$

Nepal has acknowledged the severity of AMR and is making effort to contain it at a different level. Nepal has developed the National Antibiotic Resistance Containment Action Plan, 2016 that focused on the same 5 strategic objectives. ${ }^{12}$ National Multisectoral Steering Committee under the chairmanship of Secretary-Ministry of Health and Population (MoHP) and National AMR Alliance has been formed to work jointly on AMR with representation from all related stakeholders. Though the NAP is developed, its implementation is still a challenge. Recently, Antimicrobial Resistance Containment Guideline 2076 has been approved by MoHP for healthcare facilities. The MoHP has also released National
Antibiotics Treatment Guidelines in 2014. The use of the guideline by the health workers is very low. The majority of the health workers are unaware of the guideline.

Similarly, a zero antibiotics in feed supplements policy has been developed by the Ministry of Livestock Development (MoLD), which prohibits the use of antimicrobials as growth promoters in the feed supplement. ${ }^{5}$

WHO has recommended the establishment of a national surveillance program of AMR as surveillance is fundamental to combating resistance. AMR surveillance was initiated in Nepal in 1999 by the National Public Health Laboratory (NPHL) as a focal point with nine laboratories monitoring six pathogens of interest which currently has 21 hospitals/laboratories. NPHL which also serves as the National Reference Laboratory and National Coordinating Center for AMR submits data to the GLASS since $2017 .{ }^{13}$

Though the surveillance system is in place, very few hospitals/laboratories are enrolled in the National Surveillance System. Efforts should be made to incorporate the maximum number of sites. Though other strategies are given equal priorities, negligible actions are being taken at the national level. Individual and institutional studies have been carried out. Some hospitals have implemented antibiotic stewardship programs. Some NGOs/ INGOs such as Family Health International 360 (FHI 360), Nepal Public Health Foundation-Global Antibiotic Resistance Partnership (NPHF-GARP), Nepal Public Health Research and Development Center (PHRD Nepal), and Alliance for Prudent Use of Antibiotics (APUA) are working on awareness and educational interventions that played a crucial role in AMR containment as well as on strengthening surveillance system. Though the scattered efforts are being made by individuals and institutions in all the realms of AMR, concerted action is missing.

The best way to tackle the AMR issue is to adopt the One Health $(\mathrm{OH})$ approach that brings together humans, animals, and the environmental sector. GAP has also highlighted the need for an effective $\mathrm{OH}$ approach to combat AMR and GoN has adopted it. ${ }^{11,14}$ Though the approach is the need of an hour, there are some challenges regarding its implementation. They are lack of separate institutional setup, lack of awareness among professionals in human and animal health, and environment sectors, unclear job and responsibilities, and regulatory mechanisms. ${ }^{15}$ 
For the containment of this serious health and development threat, an effective legislature and proper implementation plan are required. AMR is a multifaceted and multisectoral problem; therefore, the approach should be multisectoral and multidimensional.

\section{REFERENCES}

1. Marston HD, Dixon DM, Knisely JM, Palmore TN, Fauci AS. Antimicrobial Resistance. JAMA. 2016 Sep;316(11):1193-204. https://doi. org/10.1001/jama.2016.11764 [Google Scholar] [PubMed]

2. The Review on Antimicrobial Resistance. Tackling Drug-Resistant Infections Globally: Final Report and Recommendations. 2016. https://amrreview.org/sites/default/files/160525 Final paper with cover.pdf. [Link]

3. GARP Nepal. Situation Analysis and Recommendations; Antibiotics Use and Resistance in Nepal. 2015. https://www.cddep. org/wp-content/uploads/2017/08/garp-nepal sa.pdf. [Link]

4. WHO. Antimicrobial resistance. WHO. 2020 [cited 2021 Jul 21]. https://www.who.int/ news-room/fact-sheets/detail/antimicrobialresistance [Link]

5. Acharya KP, Wilson RT. Antimicrobial Resistance in Nepal. Front Med. 2019;6:105. https:// doi.org/10.3389/fmed.2019.00105 [Google Scholar] [PubMed]

6. CIDRAP. WHO reveals new global antibiotic resistance data, more concerns. CIDRAP. 2021. https://www.cidrap.umn.edu/newsperspective/2021/06/who-reveals-new-globalantibiotic-resistance-data-more-concerns. [Link]

7. NPHL. Antimicrobial Resistance (AMR) Surveillance Programme. 2017. https://nphl. gov.np/images/post-pictures/1495344122amr-bulletin-april.PDF. [Link]

8. Nagvekar V, Sawant S, Amey S. Prevalence of multidrug-resistant Gram-negative bacteria cases at admission in a multispeciality hospital. J Glob Antimicrob Resist. 2020 Sep;22:457-61. [Google Scholar] [ubMed]

9. Mahalmani VM, Sarma P, Prakash A, Medhi B. Positive list of antibiotics and food products: Current perspective in India and across the globe. Vol. 51, Indian journal of pharmacology. 2019. p. 231-5. [Google Scholar] [PubMed]
10. IACG. Antimicrobial resistance: national action plans. IACG. 2018. https://www.who. int/antimicrobial-resistance/interagencycoordination-group/IACG_AMR_National Action Plans 110618.pdf. [Link]

11. Global action plan on antimicrobial resistance. WHO. 2015 [cited 2021 Nov 2]. https://www. who.int/antimicrobial-resistanc/global-actionplan/en/.[Link]

12. MoHP. National Antimicrobial Resistance Containment Action Plan Nepal. MoHP. 2016. https://www.flemingfund.org/wp-content/

13. Acharya J, Zolfo M, Enbiale W, Kyaw KWY, Bhattachan M, Rijal N, et al. Quality Assessment of an Antimicrobial Resistance Surveillance System in a Province of Nepal. Trop Med Infect Dis. 2021 Apr;6(2). https://doi.org/10.3390/ tropicalmed6020060 [Google Scholar] [PubMed]

14. 14. Acharya K. National Action Plan for Antimicrobial Resistance in Nepal: Possibility of Translating Idea into Reality. Open Microbiol J. 2020;14:38-9. [Google Scholar]

15. 15. Acharya KP, Karki S, Shrestha K, Kaphle K. One health approach in Nepal: Scope, opportunities and challenges. One Heal (Amsterdam, Netherlands). 2019 Dec;8:100101. https://doi.org/10.1016/j.onehlt.2019.100101 [Google Scholar] [PubMed] 